\title{
Effect of the defected microstrip structure shapes on the performance of dual-band bandpass filter for wireless communications
}

Mussa Mabrok ${ }^{1}$, Zahriladha Zakaria ${ }^{2}$, Yully Erwanti Masrukin ${ }^{3}$, Tole Sutikno ${ }^{4}$, Hussein Alsariera $^{5}$ ${ }^{1,2,3,5}$ Center for Telecommunication Research and Innovation (CeTRI), Faculty of Electronics and Computer Engineering, Universiti Teknikal Malaysia Melaka, Malaysia

${ }^{4}$ Department of Electrical Engineering, Universitas Ahmad Dahlan, Yogyakarta, Indonesia

${ }^{4}$ Embedded System and Power Electronics Research Group (ESPERG), Yogyakarta, Indonesia

\begin{tabular}{|c|c|}
\hline Article Info & ABSTRACT \\
\hline Article history: & \multirow{10}{*}{$\begin{array}{l}\text { Due to the progression growth of multiservice wireless communication } \\
\text { systems in a single device, multiband bandpass filter has attract a great } \\
\text { attention to the end user. Therefore, multiband bandpass filter is a crucial } \\
\text { component in the multiband transceivers systems which can support multiple } \\
\text { services in one device. This paper presents a design of dual-band bandpass } \\
\text { filter at } 2.4 \mathrm{GHz} \text { and } 3.5 \mathrm{GHz} \text { for WLAN and WiMAX applications. Firstly, } \\
\text { the wideband bandpass filter is designed at a center frequency of } 3 \mathrm{GHz} \\
\text { based on quarter-wavelength short circuited stub. Three types of defected } \\
\text { microstrip structure (DMS) are implemented to produce a wide notch band, } \\
\text { which are T-inversed shape, C-shape, and U-shape. Based on the performance } \\
\text { comparisons, U-shaped DMS is selected to be integrated with the bandpass } \\
\text { filter. The designed filter achieved two passbands centered at } 2.51 \mathrm{GHz} \text { and } \\
3.59 \mathrm{GHz} \text { with } 3 \mathrm{~dB} \text { bandwidth of } 15.94 \% \text { and } 15.86 \% \text {. The proposed design } \\
\text { is very useful for wireless communication systems and its applications such } \\
\text { as WLAN and WiMAX. }\end{array}$} \\
\hline Received Apr 2, 2020 & \\
\hline Revised Jun 25, 2020 & \\
\hline Accepted Jul 22, 2020 & \\
\hline Keywords: & \\
\hline & \\
\hline Defected microstrip structure & \\
\hline Dual band & \\
\hline Wideband & \\
\hline Wireless communications & \\
\hline
\end{tabular}

This is an open access article under the CC BY-SA license.

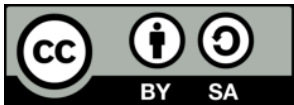

\section{Corresponding Author:}

Zahriladha Zakaria,

Center for Telecommunication Research and Innovation (CeTRI),

Faculty of Electronics and Computer Engineering,

Universiti Teknikal Malaysia Melaka,

Hang Tuah Jaya, 76100 Durian Tunggal, Melaka, Malaysia.

Email: zahriladha@utem.edu.my

\section{INTRODUCTION}

Development in wireless communication has created more potential in IEEE 802 family local area networks and metropolitan area networks. As the wireless communications benchmark are continuously transforming to boost the new features and technologies. Hence, both of base station and end-user terminal have to implement dynamic communication chains capable of supporting multi-frequency that implied by Software-defined radio (SDR) [1,2]. This SDR system will makes it easy to contain new standards with less hardware modification and reduces the time consuming. Due to the latest impositions towards the development and technology of multi-purpose RF front-ends [3, 4], which can support multiple services at the same time such as global system for mobility (GSM) and code division multiple access (CDMA) mobile cell phone services at $0.9 / 1.8 \mathrm{GHz}$, or IEEE $802.11 \mathrm{a} / \mathrm{b} / \mathrm{g}$ wireless local area local area network 
(WLAN) specifications at the 2.4/5.2-GHz bands. Therefore, a single microwave filter which can support multiple wireless applications is strongly demanded [5-9]. Many innovative multi-band bandpass filter designs have been proposed in the literature [10-23]. In order to subdivide the bandpass response into a couple of passbands (dual-band or multi-band), notch filter or band-stop filter design is required. Defected microstrip structure (DMS) is used as band-stop filter. This paper presents study and comparison of different DMS shapes responses and their effects on the performance of dual-band bandpass filter.

\section{RESEARCH METHOD}

The process of the design in this work starting with designing wide-band bandpass filter, followed by designing DMS to introduce a notch response, then integration of DMS with wide-band filter in order to produce the dual-band bandpass filter.

\subsection{Wideband bandpass filter}

In this section, wideband BPF is designed based on conventional $\lambda / 4$ short circuited stub for the frequency band 2.3-3.9 GHz to cover the wireless communication applications such as WiMAX and WLAN. The design is built based on a substrate RO4350B with $\epsilon_{r}=3.48$ and a thickness of $0.508 \mathrm{~mm}$. Figure 1 shows the physical layout of the designed microstrip $5^{\text {th }}$ order short circuit stubs BPF.

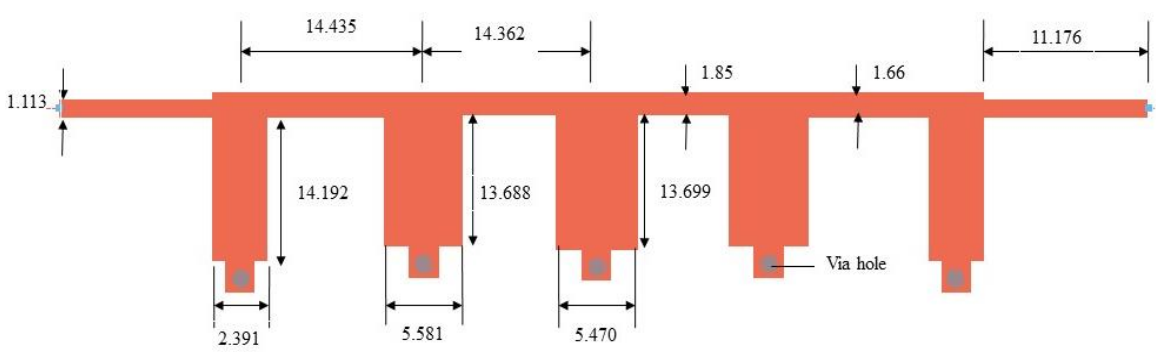

Figure 1. Layout of the designed microstrip for 5th order stub bandpass filter with quarter-wavelength short-circuited stubs

In order to get the best performance, parametric study is conducted. Where, varying the diameter of via holes may affect the response. There is a slight shift of the bandwidth to the high frequency as the radius of via holes increased as shown in Figure 2(a). Also, the various thicknesses of the substrate influence the performance of the bandpass filter. From Figure 2(b), it is observed that with increasing the thickness of the substrate, the bandwidth will be wider as well as the center frequency deviate from the preferred frequency. As a result, the radius of $0.75 \mathrm{~mm}$ and thickness of $0.508 \mathrm{~mm}$ is selected in this filter design to yield a best result. The simulation results in Figure 3 show return loss greater than $15 \mathrm{~dB}$ and insertion loss is $0.01 \mathrm{~dB}$. From the results, the filter obtains a highly selective wideband bandpass response with the fractional bandwidth of $51.6 \%$ centered at $3 \mathrm{GHz}$.

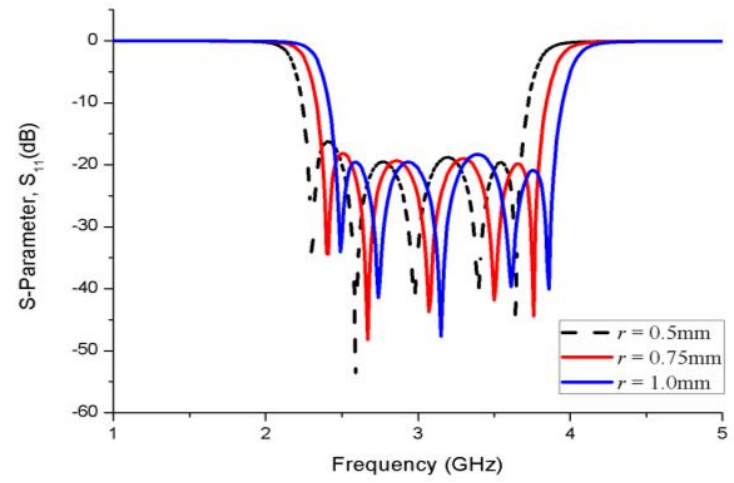

(a)

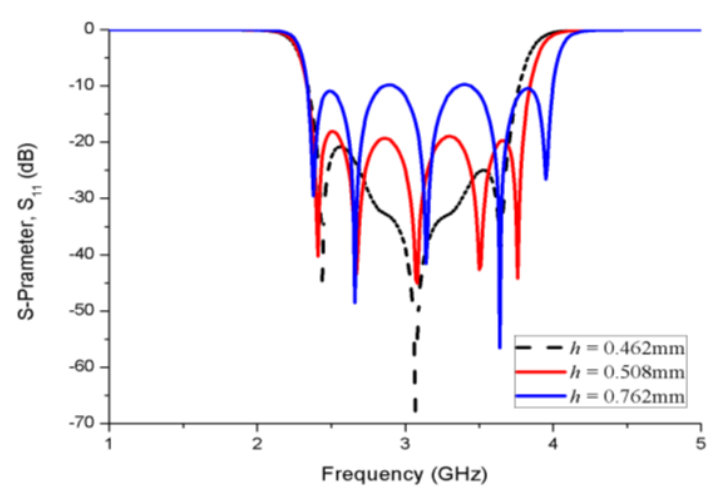

(b)

Figure 2. Shift of the bandwidth, (a) Effect diameter of via hole variation, (b) Effect of thickness substrate variation 


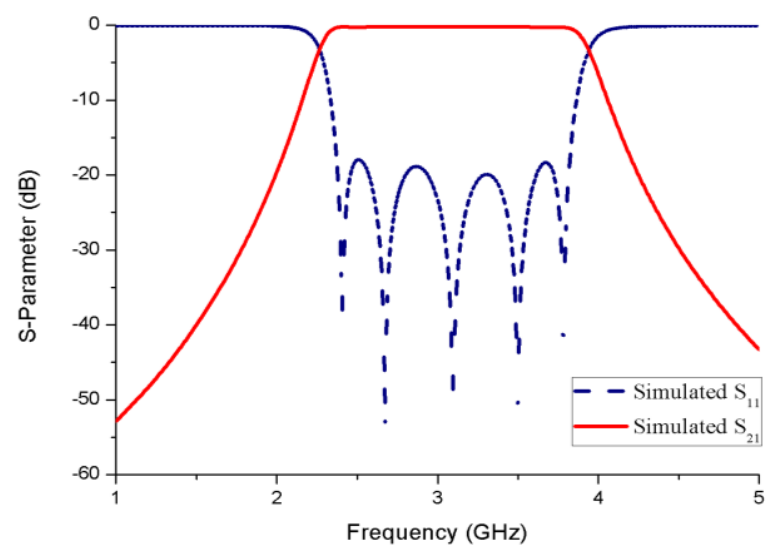

Figure 3. Simulated results of physical layout short-circuited stubs bandpass filter

\subsection{Defected microstrip structure}

With the rapid growth and development of the wireless communication systems, the demand in the introduction of notch filter within a wideband passband become higher. This notch filter is needed to eliminate the undesired interference or subdivide the bandpass response into a couple of passbands. In this section, the implementation of defected microstrip structure [24-25] in wideband response will be further discussed for dual-band bandpass filter application. This DMS is made at the notch response of $3 \mathrm{GHz}$ to remove the unwanted radio signal. Different DMS structures such as T-inversed shape, C-shape, and U- Shape are discussed and their performance are analyzed in order to assess its suitability for dual-band BPF.

\section{a. Defected microstrip structure with T-inverse shaped}

The defected microstrip structure of conventional T-inverse shaped is presented in Figure 4. This type of DMS comprises of two parts such that the black area is copper and white area is the slot structure. The DMS in the microstrip line will lead the electrical length to be higher. Other than that, this DMS also will distract the current distribution that ultimately boost the capacitance and inductance of a microstrip line. As a result, this DMS offers the characteristic of stopband and slow wave response. In order to simulate and analyze the DMS, the substrate material of roger duroid 4350 with permittivity of 3.48 and the thickness of $0.508 \mathrm{~mm}$ is used. The structure is analyzed based on the selectivity and notch of response. Therefore, the simulated results shows the notch attenuated at frequency of $3 \mathrm{GHz}$ with the dimensions of $w_{1}=0.65 \mathrm{~mm}, l_{1}=0.5 \mathrm{~mm}, w_{2}=0.45 \mathrm{~mm}, l_{2}=13.65 \mathrm{~mm}$ and characteristic impedance of $50 \Omega$ is chosen.

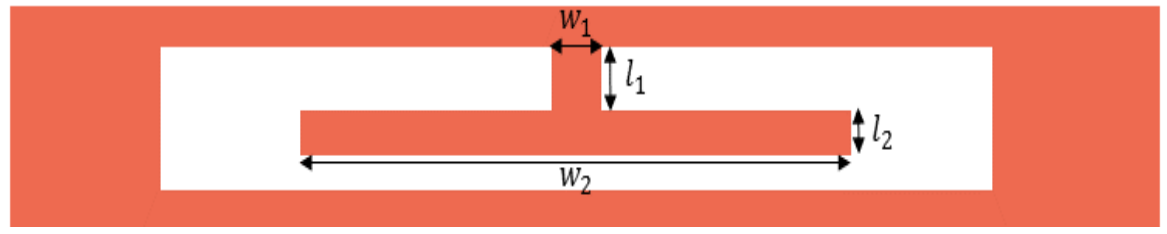

Figure 4. DMS of conventional T-inverse shaped

To investigate the characteristic of conventional T-inversed shaped of DMS, the affect structural variables of $l_{1}$ and $w_{2}$ were studied thoroughly. The various dimension of $l_{1}$ with the properties of resonant for T-inversed DMS is outlined in Figure 5(a). Meanwhile, Figure 5(b) exhibited the effect of notch response as $w_{2}$ is varied from $12.9 \mathrm{~mm}$ to $14.5 \mathrm{~mm}$. For this specific design, it can be observed as $w_{2}$ is increases, the lower the frequency it achieved. Then, the attenuation level of the notch response is greater than $40 \mathrm{~dB}$. Nevertheless, it obviously noticed that the insertion loss, $S_{21}$ on the lower frequency is poor and may influence the performance of dual-band bandpass filter as DMS implemented with bandpass filter. The parametric analysis also signifies that by altering the preferred variables in DMS structure will not enhance $S_{21}$ at lower frequency. 


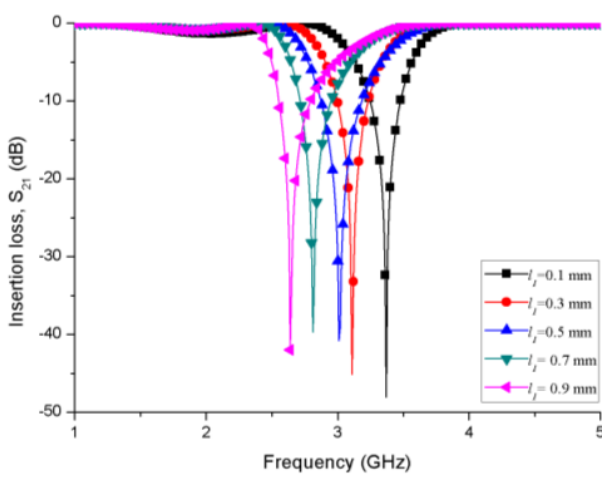

(a)

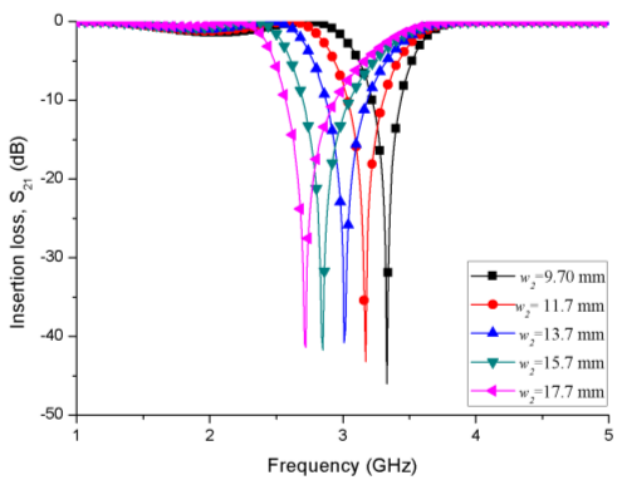

(b)

Figure 5. Relationship between dimension and properties of resonant (a) Effect of notch response when $l_{1}$ is varied, (b) Effect of notch response when $w_{2}$ is varied

\section{b. Defected microstrip structure with conventional C-shaped}

Figure 6 shows the second structure of DMS that may disrupt the current distribution on the microstrip line which is C-shaped. The DMS is developed based on Roger Duroid 4350 with permittivity and thickness of 3.48 and $0.508 \mathrm{~mm}$ respectively. This structure is designed and analyzed at the resonant frequency of $3 \mathrm{GHz}$ with the parametric analysis of selectivity and insertion loss, $S_{21}$ conducted on the notch response. The structure of C-shaped DMS notch filter comprises of a few dimensions such that $w_{1}=27.1 \mathrm{~mm}, w_{2}=3.5 \mathrm{~mm}, l_{1}=l_{2}=0.4 \mathrm{~mm}$, $l_{3}=1.2 \mathrm{~mm}$ and standard characteristic impedance of $50 \Omega$ is chosen. Therefore, the dimensions of $w_{1}$ and $l_{1}$ is chosen to perform the parametric study and examine the performance of notch response for C-shaped DMS. Figure 7(a) demonstrates the effect of varying the $w_{1}$ on the notch response. The dimension of $w_{1}$ is varied at the range of $7.1 \mathrm{~mm}$ to $47.1 \mathrm{~mm}$. As the dimension of $w_{1}$ is decreases, the resonant frequency and bandwidth attained are higher and smaller respectively. In a contrary, the insertion loss is poor as the dimension of $w_{1}$ increases. Other than that, the $l_{1}$ also one of the parameters which may affect the notch response as shown in Figure 7(b). This effect validated that increasing the length of $l_{1}$ will lead to the decreasing of resonant frequency.

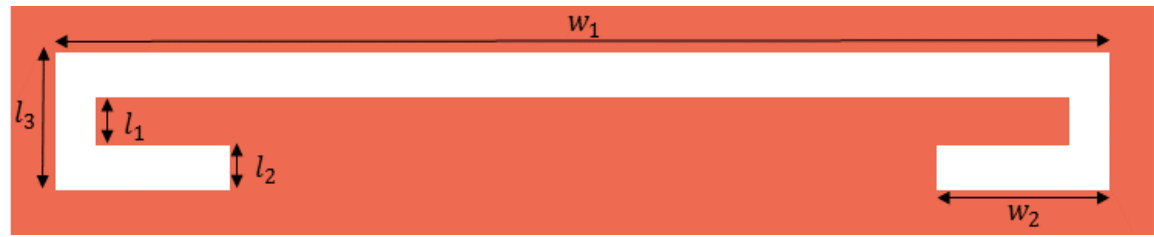

Figure 6. DMS of conventional C-inverse shaped

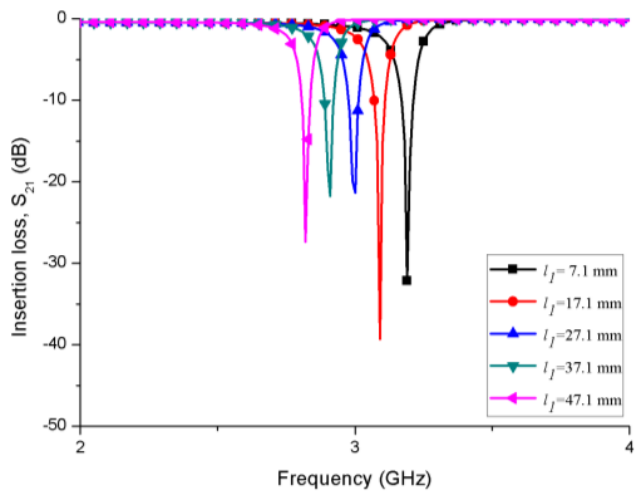

(a)

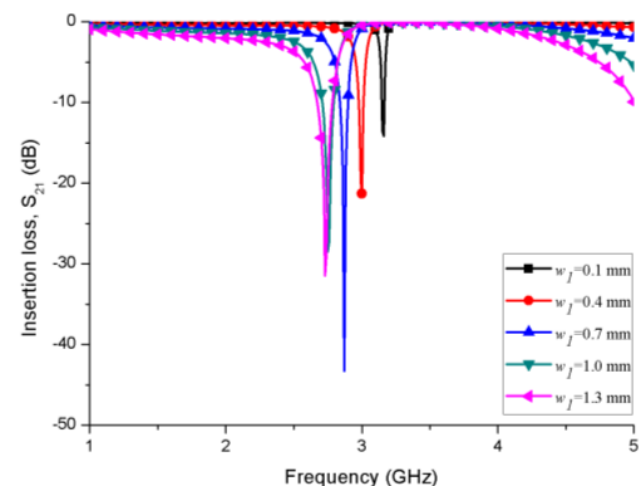

(b)

Figure 7. Performance of notch response, (a) Effect of notch response when $w_{2}$ is varied, (b) Effect of notch response when $l_{1}$ is varied 


\section{c. DMS with conventional U-shaped}

The U-shaped DMS comprises of horizontal and vertical slot in the middle of conductor line as shown in Figure 8. The DMS construction gives resonant frequency centered at $3 \mathrm{GHz}$ with the wider bandwidth and high selectivity. The substrate of roger duroid 4350 with permittivity of 3.48 and the thickness of $0.508 \mathrm{~mm}$ is used to simulate and analyze the performance of the U-shaped DMS. The simulated notch response in Figure 9 gives the attenuation level more than $-30 \mathrm{~dB}$, return loss is $-0.2 \mathrm{~dB}$, and the bandwidth of $400 \mathrm{MHz}$ at frequency of $3 \mathrm{GHz}$.

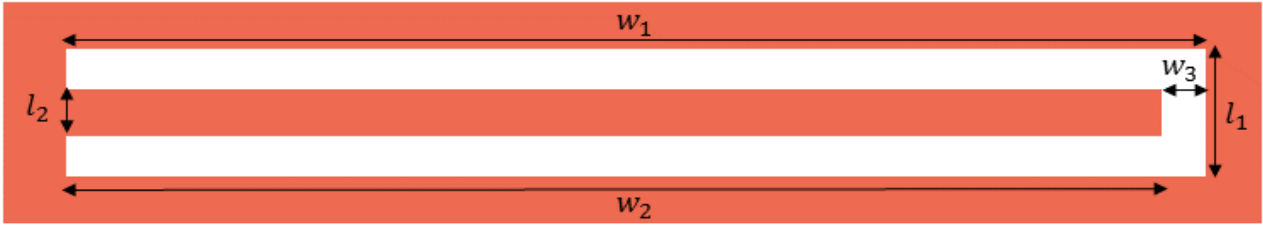

Figure 8. DMS of conventional U-inverse shaped

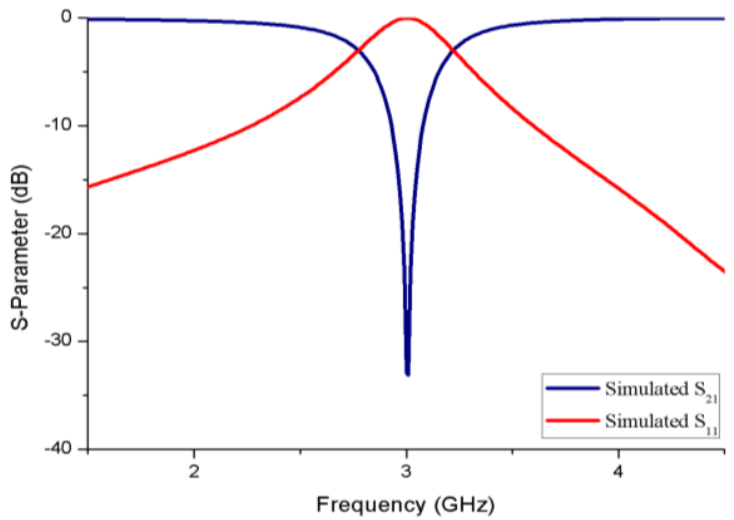

Figure 9. Simulated notch response of U-shaped DMS

The U-shaped DMS is constructed to attenuate the notch response at the preferred frequency with dimensions of $w_{1}=16.3 \mathrm{~mm}, w_{2}=16 \mathrm{~mm}, w_{3}=0.35 \mathrm{~mm}, l_{1}=1.1 \mathrm{~mm}$ and $l_{2}=0.4 \mathrm{~mm}$. The parameter of $w_{1}$ and $l_{2}$ is selected to analyze the parametric study and observe the changes on the notch response. Based on the observation from Figure 10(a) and Figure 10(b), it can be concluded that increasing the length of $w_{1}$ and $l_{2}$ will cause the decreasing in resonant frequency. However, Figure 10(b) exhibited that the insertion loss of notch response is poor and the bandwidth become wider as the dimension of $l_{2}$ increasing.

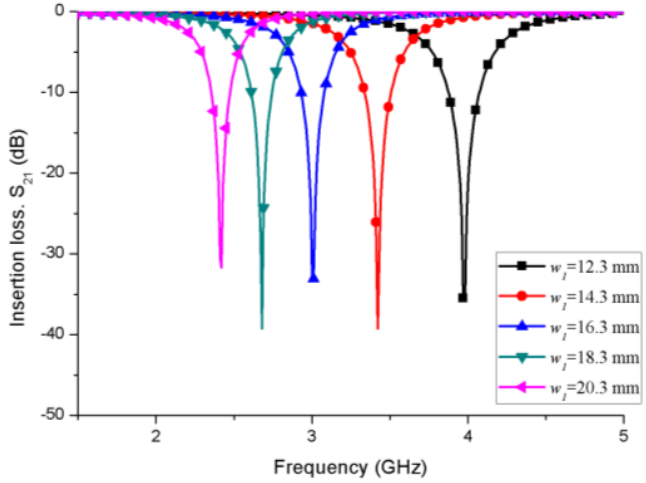

(a)

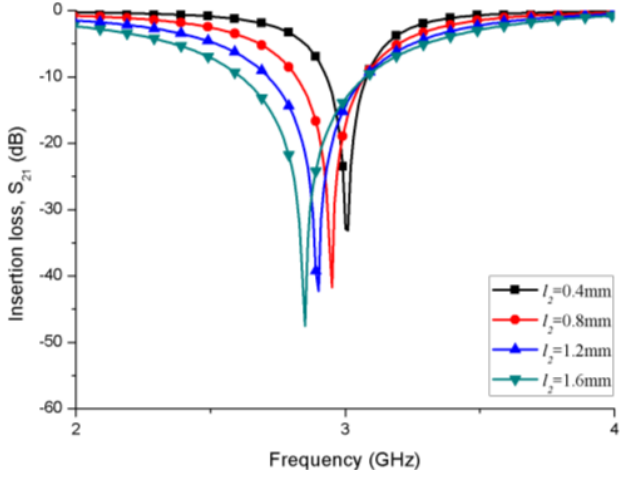

(b)

Figure 10. Notch response, (a) Effect of notch response when $w_{1}$ is varied, (b) Effect of notch response when $l_{2}$ is varied 
Figure 11 displays the comparison of simulated notch response for three types of conventional DMSs; T-inverse shaped, C-shaped, and U-shaped at frequency of $3 \mathrm{GHz}$. The performance of these DMSs are described in terms of insertion loss and bandwidth. The bandwidth for T-inverse shaped and C-shaped are quite wider and smaller compared to the U-shaped. The U-shaped DMS has the fractional bandwidth of 7.5\% which fulfilled the desired requirement for designing the dual-band bandpass filter. The U-shaped DMS also produce low and strong insertion loss rather than the DMS of T-inverse shaped and U shaped. As a result, the proposed U-shaped DMS is proved as an effective band-stop filter with wider bandwidth and high selectivity.

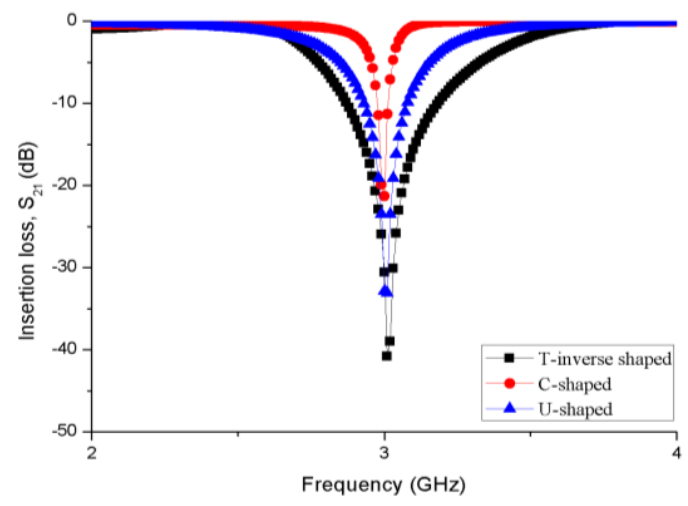

Figure 11. Comparison of simulated notch response for conventional DMS of T-inverse shaped, C-shaped and U-shaped

\section{DUAL-BAND BANDPASS FILTER}

In order to enhance the performance of dual-band bandpass filter, two structures of U-shaped DMS are placed on the transmission line of bandpass filter to produce high attenuation level and better selectivity as shown in Figure 12. Figure 13 shows that implementation of two DMSs increases the attenuation level of band reject response.

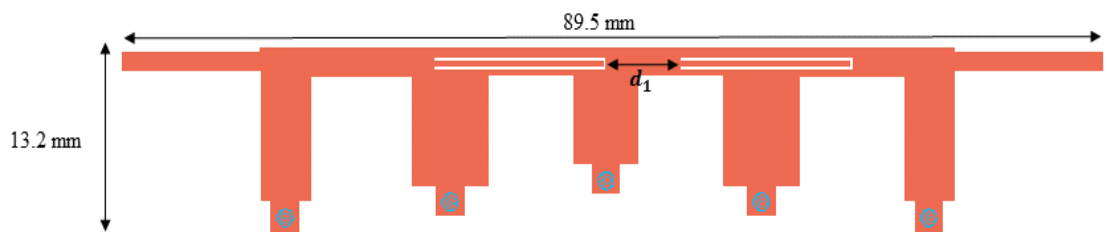

Figure 12. Proposed integrated of bandpass filter with two U-shaped DMS

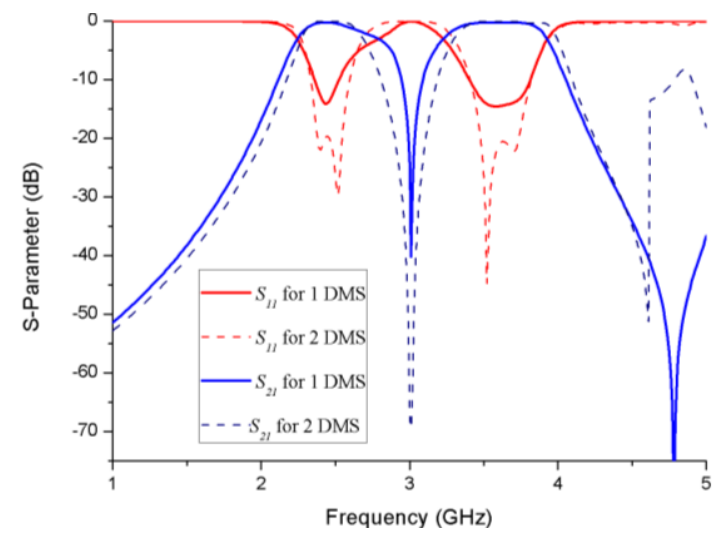

Figure 13. Comparison simulated response of a dual-band bandpass filter for the integration of one DMS and two DMSs 
The parametric study exhibited in Figure 14 proved that the distance between the two DMSs, $\mathrm{d}_{1}=6.7 \mathrm{~mm}$ is the best position to yield improved performance in return loss and insertion loss. As $d_{1}$ increases, the attenuation level of notch response is decreases and bandwidth for two passbands become wider. Other than that, the response shows the insertion loss, $S_{21}$ of dual-band bandpass filter is poor as increasing of $d_{1}$.

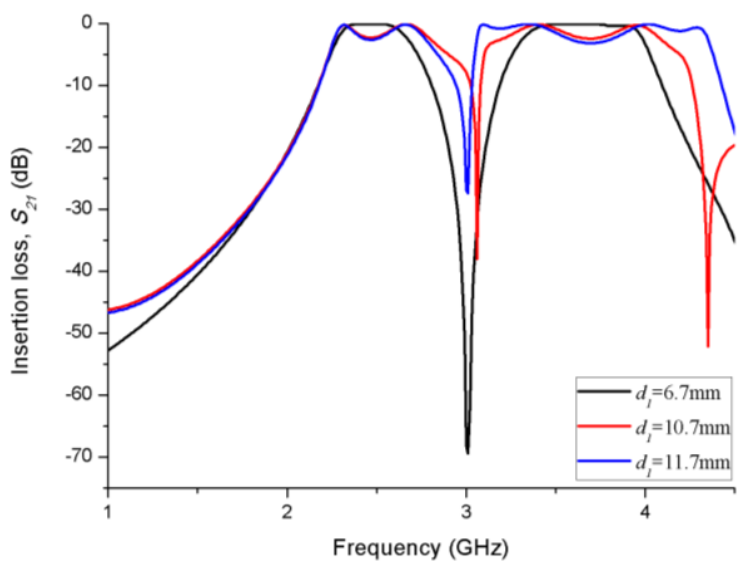

Figure 14. Effect of dual-band response as $d_{1}$ is varied

Figure 15 displays the fabricated of the integrated bandpass filter with U-shaped DMS structure. The fabricated dimension for this is approximately $89.5 \mathrm{~mm} \times 13.2 \mathrm{~mm}$. Figure 16 presented the comparison between the simulated and fabricated response of dual-band bandpass filter. From Figure 16, it can be noted that the fabricated dual-band BPF has two passbands centered at $2.51 \mathrm{GHz}$ and $3.59 \mathrm{GHz}$ with 3-dB bandwidth of $15.94 \%$ and $15.86 \%$, respectively. At the lower and upper passbands, the measured insertion losses including the loss from two SMA connectors are better than $1 \mathrm{~dB}$ respectively. The measured return losses for both passbands are greater than $15 \mathrm{~dB}$ It exhibited that the measured results achieved a good agreement with the simulated results. Slight deviation is observed due to the fabrication tolerance.

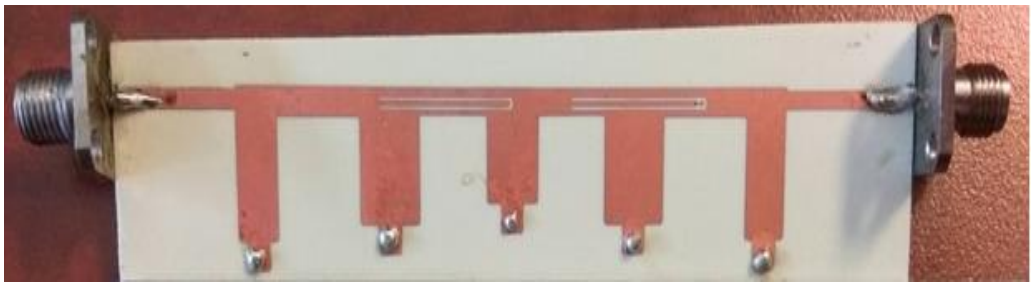

Figure 15. Fabricated of integrated bandpass filter with U-shaped DMS

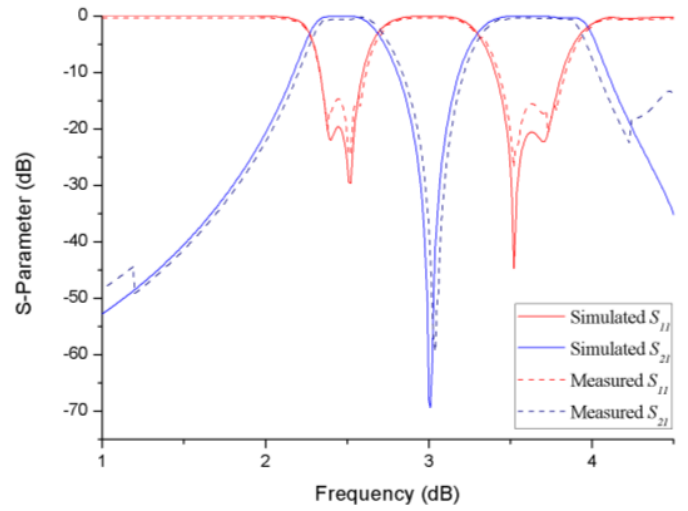

Figure 16. Simulated and measured response of proposed dual-band bandpass filter 


\section{CONCLUSION}

In this paper, the design and development of dual-band bandpass filter at frequency of $2.3-2.7 \mathrm{GHz}$ and $3.1-3.75 \mathrm{GHz}$ for WLAN and WiMAX wireless communication applications has been successfully investigated and obtained. Firstly, dual-band bandpass filter employing the topology of short circuit stubs and DMS was designed. The wideband bandpass filter was constructed using quarter wavelength short circuit stubs with a fractional bandwidth of about $51.6 \%$ at the passband with the range of $2.3 \mathrm{GHz}$ to $3.9 \mathrm{GHz}$. Three different shapes of DMS are designed and their performances have been evaluated. The obtained results from these designs indicate that the most suitable DMS is U-shape DMS due to its wider bandwidth and high selectivity. Therefore, U-shaped DMS has been introduced to the wideband bandpass filter to generate the dual-band passbands centered at $2.51 \mathrm{GHz}$ and $3.59 \mathrm{GHz}$ with FBW of about $15.94 \%$ and $15.86 \%$ respectively. The dual band filters have been simulated based on roger 4350B using advanced design system (ADS). The proposed design has been validated through an experimental work. The obtained results show good agreement between simulation and measurement results. Further research on this design can be carried out for triple-passband and introduce the tunable trait into it.

\section{ACKNOWLEDGEMENTS}

This work was supported by UTeM Zamalah Scheme. The authors gratefully acknowledge UTeM Zamalah Scheme for supporting this research work.

\section{REFERENCES}

[1] J. Raúl and Machado-Fernández, "Software Defined Radio: Basic Principles and Applications, " Revista Facultad de Ingeniería, vol. 24, no. 38, pp. 79-96, 2015.

[2] R. G. Machado and A. M. Wyglinski, "Software-Defined Radio: Bridging the Analog-Digital Divide," in Proceedings of the IEEE, vol. 103, no. 3, pp. 409-423, 2015.

[3] S. -. R. Chang, et al., "A dual-band RF transceiver for multistandard WLAN applications," IEEE Transactions on Microwave Theory and Techniques, vol. 53, no. 3, pp. 1048-1055, 2005.

[4] W.-Y. Chen, M.-H. Weng, S.-J. Chang, H. Kuan, and Y.-H. Su, "A new tri-band bandpass filter for GSM WIMAX and ultra-wideband responses by using asymmetric stepped impedance resonators," Progress In Electromagnetics Research, vol. 124, pp. 365-381, 2012.

[5] M. A. Mutalib, Z. Zakaria and N. A. Shairi, "Electronically switchable notch response for wideband bandpass applications," 12th European Conference on Antennas and Propagation (EuCAP 2018), London, pp. 1-4 2018.

[6] W. Ieu, D. Zhang and D. Zhou, "High-selectivity dual-mode dual-band microstrip bandpass filter with multitransmission zeros," Electronics Letters, vol. 53, no. 7, pp. 482-484, 2017.

[7] G. Shen, W. Che, W. Feng and Q. Xue, "Analytical Design of Compact Dual-Band Filters Using Dual Composite Right/Left-Handed Resonators," IEEE Transactions on Microwave Theory and Techniques, vol. 65, no. 3, pp. 804-814, 2017.

[8] J. Hinojosa, F. L. Martínez-Viviente, J. de Dios Ruiz and A. Alvarez-Melcon, "Modified split-ring resonator for microstrip dual- band notch filter," 2015 European Microwave Conference (EuMC), Paris, pp. 813-816, 2015.

[9] M. F. A. Khalid, Z. I. Khan, M. K. Mohd Salleh, M. R. M. Ruslan and N. A. Wahab, "Dual-band bandpass filter with rectangular shaped defective ground structure," 2015 IEEE International RF and Microwave Conference (RFM), Kuching, pp. 35-39, 2015.

[10] S. Zhang and L. Zhu, "Synthesis Design of Dual-Band Bandpass Filters With $\lambda / 4$ Stepped-Impedance Resonators," in IEEE Transactions on Microwave Theory and Techniques, vol. 61, no. 5, pp. 1812-1819, 2013.

[11] F. Bagci, A. Fernández-Prieto, A. Lujambio, J. Martel, J. Bernal and F. Medina, "Compact Balanced Dual-Band Bandpass Filter Based on Modified Coupled-Embedded Resonators," in IEEE Microwave and Wireless Components Letters, vol. 27, no. 1, pp. 31-33, 2017.

[12] M. Mabrok, Z. Zakaria, N. A. Hussin, M. A. Mutalib, "Microwave Bandpass Filter Integrated with Notch Response for Wide-band Applications, " Indonesian Journal of Electrical Engineering and Computer Science, vol. 11, no. 2, pp.797-804, 2018.

[13] W.-Y. Chen, M.-H. Weng, S.-J. Chang, H. Kuan and Y.-H. Su, "A New Tri-Band Bandpass Filter for GSM, WiMAX and Ultra-Wideband Responses by Using Asymmetric Stepped Impedance Resonators," Progress In Electromagnetics Research, vol. 124, pp. 365-381, 2012.

[14] Q. Chu and F. Chen, "A Compact Dual-Band Bandpass Filter Using Meandering Stepped Impedance Resonators," in IEEE Microwave and Wireless Components Letters, vol. 18, no. 5, pp. 320-322, 2008.

[15] H. W. Liu, et al., "Compact dual-band bandpass filter using defected microstrip structure for GPS and WLAN applications," Electronics Letters, vol. 46, no. 21, pp. 1444-1445, 2010.

[16] Jianwei Liu, et al., "Compact tri-band bandpass filter using asymmetric square ring loaded resonator," 2016 IEEE MTT-S International Microwave Workshop Series on Advanced Materials and Processes for RF and THz Applications (IMWS-AMP), Chengdu, pp. 1-3, 2016.

[17] Y. -. Lu, C. -. Hua, and T. -. Liu, "A novel dual-band bandpass filter with C-section loaded resonators," 2015 AsiaPacific Microwave Conference (APMC), Nanjing, pp. 1-3, 2015. 
[18] F. Wei, P. Qin, Y. J. Guo, and X. Shi, "Design of multi-band bandpass filters based on stub loaded steppedimpedance resonator with defected microstrip structure," IET Microwaves, Antennas \& Propagation, vol. 10, no. 2, pp. 230-236, 2016.

[19] W. Chen, Y. Zhao, and Z. Jun, "Compact and Wide Upper-Stopband Triple-Mode Broadband Microstrip BPF," Telecommunication Computing Electronics and Control, vol. 10, no. 2, pp. 353-358, 2012.

[20] E. S. Ahmed, "Compact Dual-Band Parallel Coupled T-Shaped SIR Filter for WLAN Applications, "Telecommunication Computing Electronics and Control, vol. 15, no. 4, pp. 1677-1681, 2017.

[21] M. Mabrok, Z. Zakaria, Y. E. Masrukin, T. Sutikno, A. R. Othman and N. Edward, "Switchable Dual-band Bandpass Filter Based on Stepped Impedance Resonator with U-Shaped Defected Microstrip Structure for Wireless Applications, "TELKOMNIKA Telecommunication Computing Electronics and Control, vol. 17, no. 2, pp. 1032-1039, 2019.

[22] L. Wang, Y. Xiong, L. Gong, M. Zhang, H. Li and X. Zhao, "Design of Dual-Band Bandpass Filter With Multiple Transmission Zeros Using Transversal Signal Interaction Concepts," in IEEE Microwave and Wireless Components Letters, vol. 29, no. 1, pp. 32-34, 2019.

[23] G. Liang and F. Chen, "A Compact Dual-Wideband Bandpass Filter Based on Open-/Short-Circuited Stubs," IEEE Access, vol. 8, pp. 20488-20492, 2020.

[24] D. La, Y. Lu, N. Liu and J. Zhang, "A novel compact bandstop filter using defected microstrip structure,",Microwave and Optical Technology Letters, vol. 53, pp. 433-435, 2010.

[25] D. Cheng, H.-C. Yin, and H.-X. Zheng, "Investigation on a Defected Microstrip Structure and Applications in Designing Microstrip Filters," Journal of Electromagnetic Waves and Applications, vol. 26, no, 10, pp. 37-41, 2012. 